\title{
Chemical characterization of residual lignins from eucalypt paper pulps
}

\author{
David Ibarra $^{\mathrm{a}}$, José C. del Río ${ }^{\mathrm{b}}$, Ana Gutiérrez ${ }^{\mathrm{b}}$, Isabel M. Rodríguez ${ }^{\mathrm{b}}$, \\ Javier Romero $^{c}$, María J. Martínez ${ }^{\mathrm{a}}$, Ángel T. Martínez ${ }^{\mathrm{a}, *}$ \\ ${ }^{a}$ Centro de Investigaciones Biológicas, CSIC, Ramiro de Maeztu 9, E-28040 Madrid, Spain \\ ${ }^{\mathrm{b}}$ Instituto de Recursos Naturales y Agrobiología, CSIC, PO Box 1042, E-41080 Sevilla, Spain \\ ${ }^{\mathrm{c}}$ ENCE, CIT, Carretera de Campañó s/n, E-36157 Pontevedra, Spain
}

Received 7 June 2004; accepted 28 December 2004

Available online 11 March 2005

\begin{abstract}
Residual lignins were isolated from eucalypt kraft pulps by enzymatic hydrolysis of cellulose followed by purification using a combination of proteinase hydrolysis and solvent extraction. The residual lignins isolated from brown (unbleached) and totally chlorine free (TCF) bleached pulps were analyzed by Fourier-transform infrared (FT-IR) spectroscopy and pyrolysis-gas chromatography/mass spectrometry (PyGC/MS), and compared with eucalypt milled-wood lignin and kraft lignin. The lignin in eucalypt wood and pulps showed a strong predominance of syringyl (S) over guaiacyl $(\mathrm{G})$ units. The strongest lignin modification was observed in the kraft lignin recovered from the alkaline pulping liquor. The chemical composition of the residual lignin from pulp was closer to milled-wood lignin than to the kraft lignin, indicating that most of the lignin modified during pulping was released to the cooking liquor. During TCF bleaching of pulp, which included oxygen delignification and peroxide stages, modifications of lignin were produced resulting in increased amount of non-conjugated carbonyl groups. We concluded that residual lignin in eucalypt kraft pulp reflects native lignin moieties entrapped into the cellulosic network thus partially avoiding their attack by chemical reagents, although different modifications are produced during the bleaching stages.
\end{abstract}

(C) 2005 Elsevier B.V. All rights reserved.

Keywords: Residual lignin; Syringyl/guaiacyl ratio; Paper pulp; Eucalyptus globulus; Kraft pulping; Totally chlorine free bleaching; Analytical pyrolysis; Infrared spectroscopy

\section{Introduction}

During paper pulp manufacturing wood fibers are separated using mechanical or chemical means [1,2]. The best separation and highest pulp quality are attained using kraft and other chemical pulping processes based on partial depolymerization of the lignin that forms the middle lamella between wood fibers. In this way, a suspension of cellulosic fibers is obtained, which is transformed into a sheet at the paper machine. However, a certain amount of lignin remains in fibers being responsible for the dark color of chemical pulps. The knowledge of the structure of this residual lignin is important for developing clean industrial processes to

\footnotetext{
* Corresponding author. Tel.: +34 918373112; fax: +34 915360432.

E-mail address: atmartinez@cib.csic.es (A.T. Martínez).

URL: http://www.cib.csic.es/lignina/lignina_en.html
}

obtain fully bleached pulps (for white papers) without the use of chlorine-containing reagents. Peroxide, oxygen, ozone and enzymes are among the reagents used in the new totally chlorine free (TCF) bleaching sequences.

Lignin has been traditionally isolated from pulps using acidolysis [3], however its structure can be somehow modified due to breakdown of some interunit linkages under the isolation conditions [4]. Enzymatic isolation methods have been developed with the purpose of obtaining unaltered residual lignin preparations [5]. Eucalypt wood is used as raw material for manufacturing high-quality TCF pulps in Spain and other countries. However, little is known on the chemical characteristics of the corresponding residual lignins, and the information available is mainly based on chemically isolated preparations [6,7] and in situ analysis of the whole pulp [8]. Recently, a new procedure has been optimized for the enzymatic isolation of residual lignin from 
eucalypt (Eucalyptus globulus) kraft pulps, which is based on pulp cellulose hydrolysis with two cellulolytic enzymes, and purification of the lignins obtained using a combination of proteinase treatment and extraction with two lignin solvents [9].

In the present study, the above method was applied to both brown (unbleached) and TCF-bleached eucalypt industrial pulps, and the isolated lignins were analyzed using pyrolysis-gas chromatography/mass spectrometry (Py-GC/MS) and Fourier transform-infrared (FT-IR) spectroscopy. FT-IR gave an overall picture on the lignin purity and composition [10,11], whereas Py-GC/MS provided a more detailed information including lignin composition in terms of $p$-hydroxyphenyl $(\mathrm{H})$, guayacil $(\mathrm{G})$, and syringyl (S) units $[12,13]$. To investigate chemical modifications during pulping and bleaching the residual lignins isolated from pulps were compared with unaltered lignin isolated from the eucalypt wood used as raw material [14] as well as with kraft lignin precipitated from the industrial cooking liquors [2].

\section{Experimental procedures}

\subsection{Pulp samples}

Eucalypt (E. globulus) pulps were obtained from the ENCE kraft mill in Pontevedra (Spain). They included a brown pulp with a kappa number of 15.2 (approximately $2.2 \%$ lignin content) and $40 \%$ ISO brightness, and a TCF pulp bleached with an $\mathrm{O}-\mathrm{O}-\mathrm{Q}-\mathrm{PoP}$ sequence (including double $\mathrm{O}_{2}$ treatment, chelator, $\mathrm{H}_{2} \mathrm{O}_{2}$ under pressurized $\mathrm{O}_{2}$, and atmospheric $\mathrm{H}_{2} \mathrm{O}_{2}$ ) resulting in a kappa number of 6.3 (approximately $0.9 \%$ lignin content) and $90 \%$ ISO brightness [15]. Samples were stored at $-20{ }^{\circ} \mathrm{C}$ at the humid state (with a dry matter content of approximately $30 \%$ ).

\subsection{Isolation of the residual lignins}

For isolation of residual lignins, $50 \mathrm{~g}$ of each pulp were treated with $10 \mathrm{~g}$ of Trichoderma reesei Econase CEP from AB-Enzymes (containing $4.6 \mathrm{U} / \mathrm{mg}$ endoglucanase activity estimated from glucose release from carboxymethylcellulose, and $0.2 \mathrm{U} / \mathrm{mg}$ exocellulase activity estimated from glucose release from brown eucalypt pulp) and $3.6 \mathrm{ml}$ of Aspergillus niger Novozym 188 from Novozymes (containing $80 \mathrm{U} / \mathrm{mg} \beta$-glucosidase activity estimated on $p$ nitrophenyl-glucoside, $0.6 \mathrm{U} / \mathrm{mg}$ exocellulase activity, and a protein content of $23 \mathrm{mg} / \mathrm{ml}$ ) [9]. Enzymatic hydrolysis was performed for $48 \mathrm{~h}$ at $\mathrm{pH} 5(50 \mathrm{mM}$ acetate buffer), $50{ }^{\circ} \mathrm{C}$, and $180 \mathrm{rpm}$, using $5 \%$ pulp consistency. The soluble and insoluble fractions from enzymatic hydrolysis were collected (after centrifugation at 11,000 rpm, $20 \mathrm{~min}$, $5{ }^{\circ} \mathrm{C}$, using a GSA Sorvall rotor). The insoluble fraction was washed with the above buffer until no glucose was released $\left(11,000 \mathrm{rpm}, 20 \mathrm{~min}, 5{ }^{\circ} \mathrm{C}\right.$, using a LSS-34 Sorvall rotor). From the soluble fraction (cellulase hydrolyzate) a precipitate was obtained after addition of saturated $\mathrm{NaCl}$ (1:1) and acidification to $\mathrm{pH} 2.5$ with $\mathrm{HCl}$.

\subsection{Purification of the residual lignins}

Residual lignins from the non-hydrolyzed residue and the acid-precipitable fraction from cellulase hydrolyzate, which contained contaminating protein from the enzymes used in the previous hydrolysis, were purified by a combination of enzymatic and solvent purification [9]. The first purification step was based on hydrolysis with $2 \%$ alkaline protease from Bacillus licheniformis (Subtilisin type VIII, Sigma). The reaction was conducted at $\mathrm{pH} 9.6\left(0.5 \mathrm{M} \mathrm{NaHCO}_{3}\right.$ buffer $)$ $37{ }^{\circ} \mathrm{C}$, with gentle shaking for $24 \mathrm{~h}$. The solution was centrifuged $\left(11,000 \mathrm{rpm}, 5 \mathrm{~min}, 5^{\circ} \mathrm{C}\right.$, using a $\mathrm{F} 45-12-11$ Eppendorf rotor) and both the insoluble part and the supernatant were recovered. The supernatant was acidified to $\mathrm{pH} 2.5$ with $\mathrm{HCl}$, and a precipitate was obtained. The second step was successive solvent extraction using dimethylacetamide (DMAC) and $\mathrm{NaOH}$. The two fractions from protease hydrolysis were combined, and a $50 \mathrm{mg}$ sample was dissolved at $60^{\circ} \mathrm{C}$ for $1 \mathrm{~h} \mathrm{in} 1 \mathrm{ml}$ of DMAC. The lignin fraction was precipitated by pouring the DMAC solution into diethyl ether and isolated by centrifugation $\left(13,000 \mathrm{rpm}\right.$ for $5 \mathrm{~min}$ at $5{ }^{\circ} \mathrm{C}$, using a F45-12-11 Eppendorf rotor). The fraction obtained was dissolved in $15 \mathrm{ml}$ of $0.5 \mathrm{M} \mathrm{NaOH}$ at room temperature $(1 \mathrm{~h})$. The solution was acidified to $\mathrm{pH} 2.5$, and centrifuged $(13,000 \mathrm{rpm}, 5 \mathrm{~min}$ at $5{ }^{\circ} \mathrm{C}$, using a $\mathrm{F} 45-12-11$ Eppendorf rotor) to obtain the purified residual lignin.

\subsection{Milled-wood lignin (MWL) and kraft lignin}

MWL was extracted from finely ground E. globulus sawdust using dioxane-water (9:1), precipitated and purified according to Björkman [14]. Kraft lignin was precipitated from a black liquor from industrial cooking of E. globulus wood (obtained from the ENCE mill in Pontevedra, Spain) by acidification with $\mathrm{HCl}$ (to $\mathrm{pH} 2.5$ ), washed with acidulated water ( $\mathrm{pH} 2.5)$, and dried.

\subsection{FT-IR}

FT-IR spectra were obtained with a Bruker IF-28 spectrometer using $1 \mathrm{mg}$ of lignin in $300 \mathrm{mg}$ of $\mathrm{KBr}$. A total of 50 interferograms were accumulated, and the spectra were corrected by baseline subtraction between valleys ca. 1850 and $900 \mathrm{~cm}^{-1}$.

\section{6. $P y-G C / M S$}

Pyrolyses were performed with a Curie-point flash pyrolyzer coupled to a Varian Saturn 2000 GC/MS using a $30 \mathrm{~m} \times 0.25 \mathrm{~mm}$ DB-5 column (film thickness $0.25 \mu \mathrm{m}$ ). Approximately $100 \mu \mathrm{g}$ of finely divided sample were 
deposited on a ferromagnetic wire then inserted into the glass liner and placed immediately in the pyrolyzer. The pyrolysis was carried out into the glass liner for $4 \mathrm{~s}$. The chromatograph was programmed from $40{ }^{\circ} \mathrm{C}(1 \mathrm{~min})$ to $300{ }^{\circ} \mathrm{C}$ at a rate of $6{ }^{\circ} \mathrm{C} / \mathrm{min}$. The final temperature was held for $20 \mathrm{~min}$. The injector temperature was kept at $280^{\circ} \mathrm{C}$ while the GC/MS interface was kept at $300^{\circ} \mathrm{C}$. The compounds were identified by comparison with those reported in the literature [16,17] and in the Wiley and NIST computer libraries.

\section{Results and discussion}

\subsection{Isolation of residual lignins from eucalypt pulps}

The composition of the residual lignin in eucalypt kraft pulps has already been analyzed upon Py-GC/MS of the whole pulps using single-ion chromatograms corresponding to the different G- and S-lignin units $[8,18]$. However, the low lignin content in many pulps strongly limits the possibilities for in situ analyses of residual lignins, even using single-ion chromatograms. In these cases, isolation of residual lignins from the pulps is required.

In the present study, residual lignins were obtained from brown and TCF-bleached eucalypt pulps by an enzymatic method based on cellulose hydrolysis with commercial enzymes (showing endocellulase, exocellulase and $\beta$ glucosidase activities) and recovery/purification of lignin from both the hydrolysis residue and the soluble fraction. The chemical characteristics of the different fractions obtained during optimization of the lignin isolation method were analyzed by FT-IR and Py-GC/MS. Py-GC/MS analyses during the isolation process showed variable amounts of lignin marker compounds in the non-hydrolyzed residue as well as in the acid-precipitable fraction of the hydrolyzate depending of the type of pulp (brown or TCFbleached) (see residue and hydrolyzate composition in Table 1). The main advantage of enzymatic isolation is the recovery of unaltered lignin due to the mild conditions used to remove cellulose, compared with chemical isolation that is based on an acid treatment of pulp. Its main drawback is contamination with protein as revealed by the abundance of Py-GC/MS marker compounds from phenylalanine (toluene and styrene), tyrosine (phenol, 4-methylphenol and 4-vinylphenol) and tryptophan (indole and methylindole) residues in protein (Table 1) $[19,20]$, and the amide bands (at 1655 and $1540 \mathrm{~cm}^{-1}$ ) in FT-IR spectra [21]. The protein contamination of lignin is due to the enzymes used to hydrolyze cellulose, which remain fixed on the hydrolyzate residue or coprecipitate with lignin.

After the enzymatic hydrolysis of cellulose, high-purity lignin preparations were obtained by a two-step purification including proteinase hydrolysis of contaminating protein and subsequent extractions (of combined proteinase residue and precipitable material) with two lignin solvents (DMAC and $\mathrm{NaOH}$ ). In this way, a residual lignin sample was obtained from the cellulase residue (labeled as lignin R4) and a second one from the cellulase hydrolyzate (labeled as lignin H4). The high-purity of these residual lignins was suggested by the FT-IR spectra (absence of amide bands, and broad cellulose band at $1050 \mathrm{~cm}^{-1}$ ) and confirmed by the nearly complete absence of protein and carbohydrate PyGC/MS markers (the latter being very abundant in pulp and wood samples) (see lignins R4 and H4 in Table 1, and Fig. 1).

The yields of the different lignin fractions (calculated from their kappa numbers) also varied: 20 and $1 \%$ for brown pulp lignins $\mathrm{R} 4$ and $\mathrm{H} 4$, respectively, and 0 and $1 \%$ for TCF pulp lignins R4 and H4, respectively. However, the real lignin content in pulps could be lower than estimated from kappa number due to the presence of hexenuronic acids $[22,23]$. Lignin R4 could not be obtained from the TCF pulp, because the hydrolysis residue was basically constituted of calcium oxalate (strong FT-IR bands at 1616, 1316, 778 and $661 \mathrm{~cm}^{-1}$ ), which is formed during bleaching [24], and has been reported during lignin isolation from other TCF pulps [25]. These results showed the difficulties to isolate residual lignins from TCF-bleached pulps. In the case of brown pulp, the hydrolysis residue yielded a high-purity residual lignin fraction after the combined purification used (including proteinase treatment and solvent extraction of lignin).

\subsection{Chemical characterization of residual lignins from eucalypt pulps}

Taking into account the results described in the previous section, lignins R4 from brown pulp and $\mathrm{H} 4$ from TCF pulp were selected as representative of the residual lignin in the above eucalypt pulps. Differences in the behavior of residual lignins during their enzymatic isolation had already been reported by other authors [5,26], who described that most of the lignin from high kappa number pulps was recovered from the cellulase residue whereas the amount of lignin in the cellulase hydrolyzate increased when kappa number decreased. To investigate lignin modifications during paper pulp manufacturing, the above residual lignins were analyzed using FT-IR spectroscopy and Py-GC/MS, and compared with unaltered lignin from eucalypt wood (MWL) and with the kraft lignin released from eucalypt wood during industrial cooking.

The FT-IR spectra of the residual lignins (Fig. 1, left) show typical lignin patterns $[10,11]$. They present a higher intensity of signals assigned to S-type units $\left(1329 \mathrm{~cm}^{-1}\right.$ band) than to G-type units $\left(1270 \mathrm{~cm}^{-1}\right.$ shoulder $)$. When compared with the eucalypt MWL, the purified residual lignins show no strong difference in the relative intensities of the lignin triplet bands at $1515-1421 \mathrm{~cm}^{-1}$, and the 1594 $1609 \mathrm{~cm}^{-1}$ band. By contrast, the kraft lignin showed higher intensity at $1505-15$ and $1216-1225 \mathrm{~cm}^{-1}$, and lower intensity at $1030-1033 \mathrm{~cm}^{-1}$. Another difference between these spectra concerned the intensity of the band at 1714- 
Table 1

Main compounds identified after Py-GC/MS of eucalypt wood, brown and TCF-bleached pulps, their cellulase hydrolyzates and purified residual lignins, eucalypt kraft lignin and MWL (relative molar abundances of compounds attaining $1 \%$ in at least one sample, and total S/G ratio)

\begin{tabular}{|c|c|c|c|c|c|c|c|c|c|c|c|c|c|c|}
\hline & & \multirow[t]{2}{*}{ Origin } & \multirow[t]{2}{*}{ Wood } & \multicolumn{5}{|c|}{ Brown pulp } & \multicolumn{4}{|c|}{ TCF pulp } & \multirow{2}{*}{$\begin{array}{l}\text { Kraft } \\
\text { lignin }\end{array}$} & \multirow[t]{2}{*}{ MWL } \\
\hline & & & & Pulp & Residue & $\begin{array}{l}\text { Lignin } \\
\text { R4 }\end{array}$ & Hydrolyzate & $\begin{array}{l}\text { Lignin } \\
\mathrm{H} 4\end{array}$ & Pulp & Residue & Hydrolyzate & $\begin{array}{l}\text { Lignin } \\
\mathrm{H} 4\end{array}$ & & \\
\hline 1 & 3-Hydroxypropanal & PS & 0.4 & 11.2 & 0.0 & 0.0 & 0.0 & 0.0 & 16.3 & 0.0 & 0.0 & 0.0 & 0.0 & 0.0 \\
\hline 2 & Toluene & PR & 0.0 & 0.0 & 3.1 & 0.0 & 8.2 & 0.0 & 0.0 & 14.8 & 9.0 & 0.5 & 0.0 & 0.2 \\
\hline 3 & Unknown & PS & 0.9 & 9.0 & 0.0 & 0.0 & 0.0 & 0.0 & 6.2 & 0.0 & 0.0 & 0.0 & 0.0 & 0.0 \\
\hline 4 & 2-Furaldehyde & PS & 7.7 & 6.1 & 0.6 & 0.0 & 0.2 & 3.7 & 6.9 & 0.5 & 0.0 & 0.0 & 0.0 & 0.2 \\
\hline 6 & 2-Hydroxymethylfuran & PS & 1.6 & 4.9 & 0.6 & 0.0 & 0.0 & 0.0 & 6.4 & 0.3 & 0.0 & 0.0 & 0.0 & 0.0 \\
\hline 8 & Styrene & PR & 0.0 & 0.0 & 0.3 & 0.0 & 0.7 & 0.0 & 0.0 & 0.9 & 0.8 & 0.2 & 0.0 & 1.3 \\
\hline 9 & (5H) Furan-2-one & PS & 0.7 & 4.7 & 0.0 & 0.0 & 0.0 & 0.0 & 5.6 & 0.0 & 0.0 & 0.0 & 0.0 & 0.0 \\
\hline 11 & $\begin{array}{l}\text { 2,3-Dihydro-5- } \\
\text { methylfuran-2-one }\end{array}$ & PS & 1.6 & 9.5 & 0.0 & 0.0 & 0.0 & 0.0 & 10.6 & 0.0 & 0.0 & 0.0 & 0.0 & 0.0 \\
\hline 12 & Phenol & PR & 0.0 & 0.2 & 0.6 & 0.0 & 4.6 & 0.0 & 0.2 & 5.8 & 10.3 & 0.5 & 0.0 & 0.0 \\
\hline 13 & Unknown & - & 0.0 & 0.0 & 2.0 & 0.0 & 2.2 & 0.0 & 0.0 & 9.3 & 6.8 & 0.0 & 0.0 & 0.0 \\
\hline 14 & 5,6-Dihydropyran-2,5-dione & PS & 1.3 & 2.4 & 0.0 & 0.0 & 0.0 & 0.0 & 2.2 & 0.0 & 0.0 & 0.0 & 0.0 & 0.0 \\
\hline 15 & $\begin{array}{l}\text { 4-Hydroxy-5,6-dihydro- } \\
(2 \mathrm{H}) \text {-pyran-2-one }\end{array}$ & PS & 5.9 & 2.3 & 0.5 & 2.3 & 0.0 & 2.4 & 2.4 & 0.0 & 0.0 & 0.0 & 0.0 & 0.0 \\
\hline 17 & $\begin{array}{l}\text { 2-Hydroxy-3-methyl-2- } \\
\text { cyclopenten-1-one }\end{array}$ & PS & 0.4 & 5.7 & 0.0 & 0.0 & 0.0 & 0.0 & 6.0 & 0.0 & 0.0 & 0.0 & 0.0 & 0.0 \\
\hline 21 & 4-Methylphenol & PR & 0.0 & 0.0 & 2.9 & 0.0 & 11.3 & 0.0 & 0.0 & 11.3 & 11.7 & 0.2 & 0.0 & 0.0 \\
\hline 23 & Guaiacol & LG & 0.9 & 0.3 & 3.0 & 2.7 & 1.4 & 4.5 & 0.0 & 1.5 & 0.1 & 2.2 & 3.1 & 2.8 \\
\hline 24 & Levoglucosenone & PS & 0.7 & 0.0 & 1.4 & 0.0 & 1.5 & 0.0 & 0.0 & 4.6 & 3.3 & 0.0 & 0.0 & 0.0 \\
\hline 26 & 3,4-Dihydroxybenzaldehyde & - & 0.6 & 1.0 & 0.0 & 0.0 & 0.0 & 0.0 & 0.9 & 0.0 & 0.0 & 0.0 & 0.0 & 0.0 \\
\hline 28 & 4-Methylguaiacol & LG & 0.9 & 0.0 & 2.5 & 1.0 & 0.5 & 2.4 & 0.0 & 0.3 & 0.0 & 0.6 & 1.1 & 1.2 \\
\hline 29 & Catechol & PS & 0.4 & 6.3 & 0.0 & 0.0 & 0.0 & 0.0 & 6.6 & 0.0 & 0.0 & 0.0 & 0.3 & 1.0 \\
\hline 30 & 4-Vinylphenol & PR & 0.0 & 0.0 & 0.4 & 0.0 & 1.2 & 0.0 & 0.0 & 1.5 & 1.7 & 0.4 & 0.0 & 0.2 \\
\hline 31 & 5-Hydroxymethyl-2-furaldehyde & PS & 4.0 & 1.7 & 0.0 & 0.0 & 0.0 & 0.0 & 1.8 & 0.0 & 0.0 & 0.0 & 0.0 & 0.0 \\
\hline 32 & 3-Methoxycatechol ${ }^{\mathrm{a}}$ & LM & 0.3 & 0.0 & 2.2 & 0.9 & 1.0 & 2.0 & 0.0 & 0.0 & 0.0 & 1.2 & 4.8 & 1.2 \\
\hline 33 & 3-Methylcatechol & PS & 0.0 & 2.4 & 0.0 & 0.0 & 0.0 & 0.0 & 1.6 & 0.0 & 0.0 & 0.0 & 0.0 & 0.0 \\
\hline 34 & 4-Ethylguaiacol & LG & 0.2 & 0.5 & 0.4 & 1.1 & 0.2 & 1.6 & 0.6 & 0.0 & 0.0 & 0.3 & 0.3 & 0.5 \\
\hline 35 & 1,4-Benzenediol & PS & 0.0 & 1.3 & 0.0 & 0.0 & 0.0 & 0.0 & 1.6 & 0.0 & 0.0 & 0.0 & 0.0 & 0.0 \\
\hline 36 & 4-Methylcatechol & PS & 0.0 & 0.7 & 0.0 & 0.0 & 0.0 & 0.0 & 1.1 & 0.0 & 0.0 & 0.0 & 0.0 & 0.1 \\
\hline 37 & Indole & PR & 0.0 & 0.0 & 4.3 & 0.0 & 24.8 & 0.2 & 0.0 & 21.3 & 29.4 & 1.3 & 0.0 & 0.0 \\
\hline 38 & 4-Hydroxybenzaldehyde & PS & 0.0 & 3.2 & 0.0 & 0.0 & 0.0 & 0.0 & 2.8 & 0.0 & 0.0 & 0.0 & 0.0 & 0.0 \\
\hline 39 & 4-Vinylguaiacol & LG & 3.0 & 0.4 & 6.0 & 4.8 & 1.9 & 4.4 & 0.0 & 1.8 & 0.1 & 4.3 & 2.2 & 6.9 \\
\hline 40 & 2-Methyl-1,4-benzenediol & PS & 0.0 & 1.1 & 0.0 & 0.0 & 0.0 & 0.0 & 1.2 & 0.0 & 0.0 & 0.0 & 0.0 & 0.0 \\
\hline 41 & Syringol & LS & 3.0 & 1.6 & 7.9 & 10.5 & 3.5 & 15.7 & 0.3 & 0.9 & 0.1 & 6.9 & 14.7 & 8.1 \\
\hline 42 & Eugenol & LG & 0.6 & 0.0 & 0.7 & 1.8 & 0.0 & 0.6 & 0.0 & 0.0 & 0.0 & 0.1 & 0.0 & 0.4 \\
\hline 44 & Pyrogallol & PS & 0.3 & 4.0 & 0.0 & 0.0 & 0.0 & 0.0 & 2.8 & 0.0 & 0.0 & 0.0 & 0.0 & 6.5 \\
\hline 46 & 1,6-Anhydrogalactopyranose & PS & 1.4 & 0.0 & 0.7 & 0.0 & 0.0 & 0.0 & 0.0 & 4.2 & 0.0 & 0.0 & 0.0 & 0.0 \\
\hline 47 & Methylindole & PR & 0.0 & 0.0 & 1.1 & 0.0 & 8.5 & 0.3 & 0.0 & 3.1 & 6.5 & 0.3 & 0.0 & 0.0 \\
\hline 48 & Vanillin & LG & 0.9 & 0.1 & 0.4 & 3.6 & 0.0 & 0.8 & 0.0 & 0.0 & 0.0 & 1.1 & 5.1 & 1.4 \\
\hline 52 & 4-Methylsyringol & LS & 2.3 & 0.3 & 3.4 & 3.5 & 0.9 & 7.9 & 0.0 & 1.3 & 0.2 & 2.3 & 4.3 & 3.8 \\
\hline 53 & 1,6-Anhydromannopyranose & PS & 0.0 & 0.0 & 1.7 & 0.0 & 17.4 & 0.0 & 0.0 & 0.3 & 15.7 & 0.0 & 0.0 & 0.0 \\
\hline 54 & trans-Isoeugenol & LG & 2.2 & 0.1 & 2.4 & 4.6 & 0.2 & 3.1 & 0.0 & 0.6 & 0.0 & 1.0 & 0.5 & 3.5 \\
\hline 56 & Acetoguaiacone & LG & 0.4 & 0.0 & 0.7 & 0.7 & 0.0 & 0.6 & 0.0 & 0.0 & 0.3 & 0.5 & 1.0 & 0.5 \\
\hline 57 & Levoglucosane & PS & 12.5 & 11.4 & 1.9 & 0.0 & 2.9 & 0.0 & 8.5 & 5.6 & 3.2 & 0.0 & 0.0 & 0.0 \\
\hline 59 & tert-Butylphenol & $\mathrm{C}$ & 0.0 & 0.0 & 0.4 & 0.0 & 0.0 & 0.0 & 1.0 & 4.0 & 0.2 & 0.1 & 0.0 & 0.0 \\
\hline 60 & $\mathrm{~S}_{6}$ & $\mathrm{CR}$ & 0.0 & 0.0 & 0.0 & 0.0 & 0.0 & 0.0 & 0.0 & 0.0 & 0.0 & 0.0 & 1.6 & 0.0 \\
\hline 62 & Unknown & PS & 0.0 & 0.7 & 0.0 & 0.0 & 0.0 & 0.0 & 1.0 & 0.0 & 0.0 & 0.0 & 0.0 & 0.0 \\
\hline 63 & 4-Ethylsyringol & LS & 0.8 & 0.3 & 0.3 & 1.2 & 0.2 & 3.7 & 0.1 & 0.0 & 0.0 & 0.6 & 1.1 & 1.5 \\
\hline 64 & Guaiacylacetone & LG & 0.6 & 0.0 & 0.6 & 2.0 & 0.1 & 1.3 & 0.0 & 0.0 & 0.0 & 0.5 & 0.2 & 0.6 \\
\hline 65 & 4-Vinylsyringol & LS & 8.0 & 0.7 & 11.0 & 13.5 & 3.8 & 9.6 & 0.1 & 2.3 & 0.1 & 9.7 & 5.4 & 13.5 \\
\hline 66 & 2,6-Dimethoxybenzoquinone & LM & 0.0 & 0.0 & 0.0 & 0.0 & 0.0 & 0.0 & 0.0 & 0.0 & 0.0 & 0.0 & 13.1 & 0.0 \\
\hline 69 & 4-Allylsyringol & LS & 2.2 & 0.1 & 1.9 & 3.5 & 0.4 & 3.5 & 0.0 & 0.2 & 0.0 & 1.1 & 0.6 & 1.7 \\
\hline 71 & cis-4-Propenylsyringol & LS & 1.3 & 0.0 & 1.0 & 2.6 & 0.2 & 2.3 & 0.0 & 0.2 & 0.0 & 0.5 & 0.2 & 1.6 \\
\hline 72 & Dimethoxythiophenol & LM & 0.0 & 0.0 & 0.0 & 0.0 & 0.0 & 0.0 & 0.0 & 0.0 & 0.0 & 0.0 & 1.0 & 0.0 \\
\hline 73 & Syringaldehyde & LS & 3.6 & 0.2 & 1.4 & 7.2 & 0.2 & 4.3 & 0.0 & 0.0 & 0.0 & 4.2 & 18.4 & 4.4 \\
\hline 74 & Homosyringaldehyde & LS & 2.9 & 0.2 & 0.0 & 0.0 & 0.0 & 0.0 & 0.1 & 0.0 & 0.0 & 0.0 & 0.4 & 1.8 \\
\hline 75 & trans-4-Propenylsyringol & LS & 8.4 & 0.3 & 9.3 & 19.2 & 2.0 & 12.4 & 0.1 & 2.3 & 0.3 & 4.7 & 1.5 & 9.3 \\
\hline 76 & Acetosyringone & LS & 1.2 & 0.1 & 0.6 & 3.0 & 0.1 & 3.5 & 0.0 & 0.0 & 0.0 & 1.4 & 6.5 & 1.7 \\
\hline 77 & trans-Coniferaldehyde & LG & 2.2 & 0.0 & 0.0 & 0.6 & 0.0 & 0.0 & 0.0 & 0.0 & 0.0 & 0.0 & 0.0 & 2.6 \\
\hline 78 & trans-Coniferyl alcohol & LG & 0.4 & 0.0 & 5.5 & 0.1 & 0.0 & 0.0 & 0.0 & 0.0 & 0.0 & 6.3 & 0.0 & 4.8 \\
\hline
\end{tabular}




\begin{tabular}{|c|c|c|c|c|c|c|c|c|c|c|c|c|c|c|}
\hline & & \multirow[t]{2}{*}{ Origin } & \multirow[t]{2}{*}{ Wood } & \multicolumn{5}{|c|}{ Brown pulp } & \multicolumn{4}{|c|}{ TCF pulp } & \multirow{2}{*}{$\begin{array}{l}\text { Kraft } \\
\text { lignin }\end{array}$} & \multirow[t]{2}{*}{ MWL } \\
\hline & & & & Pulp & Residue & $\begin{array}{l}\text { Lignin } \\
\text { R4 }\end{array}$ & Hydrolyzate & $\begin{array}{l}\text { Lignin } \\
\mathrm{H} 4\end{array}$ & Pulp & Residue & Hydrolyzate & $\begin{array}{l}\text { Lignin } \\
\mathrm{H} 4\end{array}$ & & \\
\hline 79 & Syringylacetone & LS & 1.9 & 0.2 & 0.7 & 6.2 & 0.0 & 5.0 & 0.0 & 0.0 & 0.0 & 2.8 & 0.3 & 1.4 \\
\hline 81 & Propiosyringone & LS & 0.4 & 0.0 & 0.0 & 2.2 & 0.0 & 2.0 & 0.0 & 0.0 & 0.0 & 0.1 & 0.8 & 0.6 \\
\hline 82 & cis-Sinapyl alcohol & LS & 0.9 & 0.0 & 0.0 & 0.0 & 0.0 & 0.0 & 0.0 & 0.0 & 0.0 & 1.4 & 0.0 & 1.0 \\
\hline 83 & trans-Sinapaldehyde & LS & 7.5 & 0.0 & 0.0 & 0.0 & 0.0 & 0.3 & 0.0 & 0.1 & 0.0 & 0.7 & 0.0 & 6.6 \\
\hline 84 & trans-Sinapyl alcohol & LS & 0.0 & 0.0 & 5.1 & 0.0 & 0.0 & 0.0 & 0.0 & 0.2 & 0.0 & 41.2 & 0.0 & 4.3 \\
\hline 85 & Anthraquinone & CR & 0.0 & 0.0 & 10.1 & 0.0 & 0.1 & 0.0 & 0.0 & 0.0 & 0.0 & 0.0 & 2.5 & 0.0 \\
\hline \multirow[t]{2}{*}{86} & $\mathrm{~S}_{8}$ & CR & 0.0 & 0.0 & 0.0 & 0.0 & 0.0 & 0.0 & 0.0 & 0.0 & 0.0 & 0.0 & 7.0 & 0.0 \\
\hline & $\mathrm{S} / \mathrm{G}$ molar ratio & & 3.1 & 2.6 & 1.9 & 3.1 & 2.5 & 3.5 & 1.1 & 1.8 & 1.4 & $2.1^{\mathrm{b}}$ & 4.8 & 2.6 \\
\hline
\end{tabular}

Origin of compounds: LG, G-type lignin; LS, S-type lignin; LM, modified lignin; PS, polysaccharide; PR, protein; C, contaminant; and CR, cooking reagent.

a Not included in $\mathrm{S} / \mathrm{G}$ ratio estimation.

b Cinnamyl alcohols excluded (if these compounds are included a S/G ratio of 4.5 was obtained).

$1725 \mathrm{~cm}^{-1}$ that is assigned to non-conjugated carbonyls [21]. A higher intensity of this band, and that at 1594$1596 \mathrm{~cm}^{-1}$, was found in the TCF pulp residual lignin compared with the brown pulp lignin.

The Py-GC/MS analysis of eucalypt MWL, residual lignins from brown and TCF-bleached pulps and kraft lignin (Fig. 1, right) showed a strong predominance of ligninderived phenolic compounds (Table 1) [13]. These include guaiacol (peak 23), 4-methylguaiacol (peak 28), 4-ethylguaiacol (peak 34), 4-vinylguaiacol (peak 39), 4-allylguaiacol or eugenol (peak 42), trans-4-propenylguaiacol or transisoeugenol (peak 54), vanillin (peak 48), homovanillin (small peak 55), acetoguaiacone (peak 56), guaiacylacetone (peak 64), propiovanillone (small peak 67), trans-coniferaldehyde (peak 77) and trans-coniferyl alcohol (peak 78) from G lignin units; and syringol (peak 41), 4-methylsyringol (peak 52), 4-ethylsyringol (peak 63), 4-vinylsyringol (peak 65), 4-allylsyringol (peak 69), cis- and trans-4propenylsyringol (peaks 71 and 75), syringaldehyde (peak 73), homosyringaldehyde (peak 74), acetosyringone (peak 76), syringylacetone (peak 79), propiosyringone (peak 81), cis- and trans-synapyl alcohols (peaks 82 and 84) and transsinapaldehyde (peak 83) from S lignin units.

While the pyrogram of eucalypt MWL was dominated by syringol (peak 41), 4-vinylsyringol (peak 65), trans-4propenylsyringol (peak 75), trans-sinapaldehyde (peak 83) and trans-sinapyl alcohol (peak 84), the pyrogram of eucalypt kraft lignin was dominated by the two former peaks (syringol and 4-vinylsyringol) but also by the oxidized compounds syringaldehyde (peak 73) and acetosyringone (peak 76). Interestingly, the pyrograms of both brown and TCF pulp residual lignins showed a distribution of lignin marker compounds more similar to that of the eucalypt MWL than to the kraft lignin.

The S/G molar ratio of the brown pulp residual lignin R4 was only slightly higher than estimated in situ by Py-GC/MS of the whole pulp, but a stronger difference between S/G estimation in situ and after residual lignin isolation was found in the case of TCF pulp (Table 1). The extremely low lignin content in bleached pulps strongly limits the possibility to estimate the $S / G$ ratio in pyrograms from the whole pulp and, therefore, the ratio obtained from the isolated lignin could be more reliable.

The lignin in eucalypt wood and pulps (analyzed in situ and after isolation) showed a strong predominance of $\mathrm{S}$ units, as evidenced by both FT-IR and Py-GC/MS analyses. The S/G molar ratio of eucalypt wood estimated by Py-GC/ MS was similar to those reported in the literature [12,18], and only slightly higher than found when analyzing MWL. Similar ratios were obtained also for the brown pulp lignin analyzed in situ or after enzymatic isolation. Although a decrease of S/G ratio during kraft cooking of eucalypt wood has been suggested [7], no strong differences were found here. In a similar way, only slight differences between native lignin in eucalypt wood and residual lignin in brown pulp were revealed by FT-IR.

During TCF bleaching of the eucalypt pulp, some modifications in the lignin structure were produced including increased amount of non-conjugated carbonyls. The increase of carboxylic acids during oxygen delignification and peroxide bleaching of other pulps has been reported after analyzing acidolysis or enzymatic residual lignins [2729]. Moreover, a modification of lignin $S / G$ ratio seems to be produced during TCF bleaching both when lignin was analyzed in situ or after enzymatic isolation. In this sense, it has been shown by modified nitrobenzene degradation that residual lignin from TCF-bleached pulp has a higher content of condensed structures than brown pulp residual lignin [26].

However, the strongest modification of eucalypt lignin was observed in the kraft lignin. This includes a high S/G ratio, which suggests that S-type lignin (less condensed than G-lignin because of absence of 5-5 linkages) is more easily solubilized during cooking. Important differences were also found in the FT-IR spectra of kraft lignin. The signal assigned to carboxyl groups showed lower intensity than in the TCF lignin, but high intensities were observed at 1216 and $1515 \mathrm{~cm}^{-1}$. These bands, which were displaced with respect to the other lignins, could be partially due to phenolic units that are very abundant in eucalypt kraft lignin [30]. PyGC/MS of kraft lignin released some lignin-derived compounds that were not found during the analysis of the other samples, such as 2,6-dimethoxybenzoquinone, prob- 

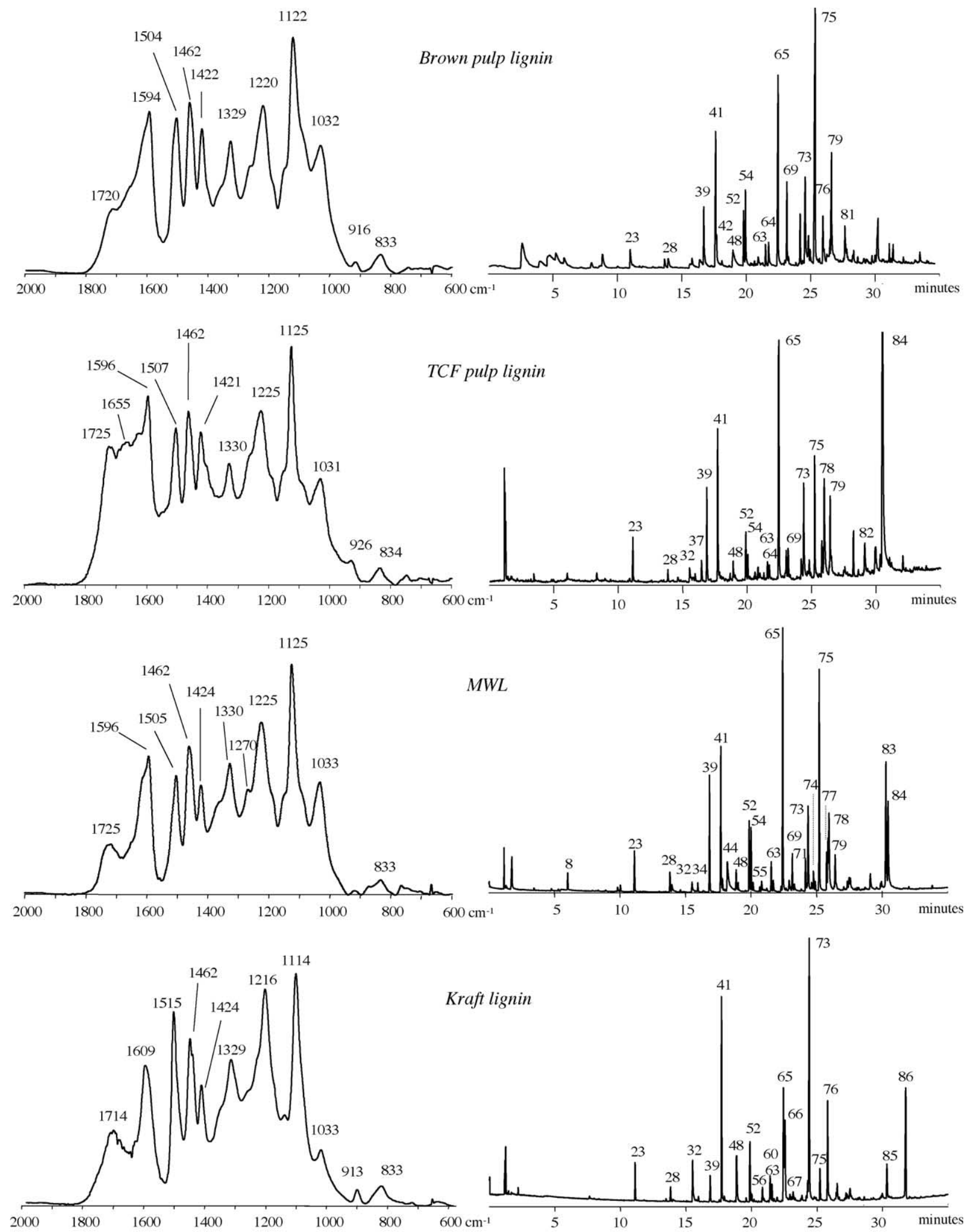

Fig. 1. FT-IR spectra, 2000-600 $\mathrm{cm}^{-1}$ region (left), and Py-GC/MS chromatograms (right) of residual lignins isolated by cellulase hydrolysis of brown (R4 from cellulase residue) and TCF-bleached ( $\mathrm{H} 4$ from cellulase hydrolyzate) purified by a combination of protease treatment and solvent extraction, compared with MWL isolated from eucalypt wood, and kraft lignin recovered from alkaline cooking liquor. The TCF lignin pyrogram was scaled-up for clarity (peak 84 is out of the scale). See Table 1 for identification of main Py-GC/MS peaks. 
ably formed after alkyl-aryl breakdown of phenolic units, 3methoxycathecol, probably derived also from altered (demethylated) S units, and dimethoxythiophenol, formed by sulfur incorporation to $\mathrm{S}$ units during kraft pulping that uses $\mathrm{Na}_{2} \mathrm{~S}$ and $\mathrm{NaOH}$ as cooking reagents $\left(\mathrm{S}_{6}\right.$ and $\mathrm{S}_{8}$ were also released by pyrolysis). Py-GC/MS of kraft lignin released also higher amount of both G- and S-type aromatic aldehydes and ketones, which could originate from scission of $\beta$-aryl ether linkages during cooking. Simultaneously, lower amounts of vinylsyringol and propenylsyringol (and their G-type counterparts) were released from kraft lignin in agreement with the low amount of $\mathrm{C}_{\beta}$ ether linkages [19].

It is possible to conclude that the eucalypt residual lignins show a chemical composition more similar to MWL than to kraft lignin. This indicates that the most heavily modified lignin during wood cooking is released and incorporates to black liquor, whereas the residual lignin in pulp remains less severely altered [28]. Then, oxidative alteration of the eucalypt residual lignin is produced during TCF bleaching.

\section{Acknowledgements}

This study has been supported by ENCE, the EUContract QLK5-99-1357, and the Spanish project AGL2002-00393. AG acknowledges a "Ramón y Cajal" contract of the Spanish MCyT, and DI a I3P Fellowship from the Spanish CSIC ("Bioremediation and Phytoremediation" network). AB-Enzymes (Finland) and Novozymes (Denmark) are acknowledged for samples of several commercial enzymes.

\section{References}

[1] D. Fengel, G. Wegener, Wood: Chemistry, Ultrastructure, Reactions, De Gruyter, Berlin, 1984.

[2] E. Sjöström, Wood Chemistry. Fundamentals and Applications, Academic Press, San Diego, 1993.

[3] G. Gellerstedt, J. Pranda, J. Wood Chem. Technol. 14 (1994) 467-482.

[4] K. Lundquist, in: S.Y. Lin, C.W. Dence (Eds.), Methods in Lignin Chemistry, Springer-Verlag, Berlin, 1992, pp. 289-300.
[5] B. Hortling, M. Ranua, J. Sundquist, Nordic Pulp Paper Res. J. 5 (1990) 33-37.

[6] A.P. Duarte, D. Robert, D. Lachenal, Holzforschung 54 (2000) $365-$ 372.

[7] A.P. Duarte, D. Robert, D. Lachenal, Holzforschung 55 (2001) 645651.

[8] J.C. del Río, A. Gutiérrez, J. Romero, M.J. Martínez, Á.T. Martínez, J. Anal. Appl. Pyrolysis 58/59 (2001) 425-433.

[9] D. Ibarra, J.C. del Río, A. Gutiérrez, I.M. Rodríguez, J. Romero, M.J. Martínez, Á.T. Martínez, Enzyme Microb. Technol. 35 (2004) 173181.

[10] O. Faix, in: S.Y. Lin, C.W. Dence (Eds.), Methods in Lignin Chemistry, Springer-Verlag, Berlin, 1992, pp. 83-109.

[11] G. Vázquez, G. Antorrena, J. González, S. Freire, Holzforschung 51 (1997) 158-166.

[12] J.C. del Río, M. Speranza, A. Gutiérrez, M.J. Martínez, ÁT. Martínez, J. Anal. Appl. Pyrolysis 64 (2002) 421-431.

[13] D. Meier, O. Faix, in: S.Y. Lin, C.W. Dence (Eds.), Methods in Lignin Chemistry, Springer-Verlag, Berlin, 1992, pp. 177-199.

[14] A. Björkman, Sven. Papperstidn. 13 (1956) 477-485.

[15] International Organisation for Standardization Documentation and Information (ISO), ISO Standards Handbook, ISO, Geneva, 1998.

[16] J. Ralph, R.D. Hatfield, J. Agric. Food Chem. 39 (1991) 1426-1437.

[17] O. Faix, D. Meier, I. Fortmann, Holz Roh-Werkstoff 48 (1990) 351354.

[18] D.V. Evtuguin, C.P. Neto, A.M.S. Silva, P.M. Domingues, F.M.L. Amado, D. Robert, O. Faix, J. Agric. Food Chem. 49 (2001) 42524261.

[19] J.-W. Choi, O. Faix, D. Meier, Holzforschung 55 (2001) 185-192.

[20] G. Almendros, Á.T. Martínez, A.E. González, F. Martín, F.J. González-Vila, Mycol. Res. 94 (1990) 211-218.

[21] J. Dorado, G. Almendros, J.A. Field, R. Sierra-Alvarez, Enzyme Microb. Technol. 28 (2001) 550-559.

[22] F.S. Chakar, L. Allison, T.J. McDonough, A.J. Ragauskas, in: Proceedings of the EWLP'2000, Bordeaux, September 3-6, 2000, , pp. 253-256.

[23] J. Li, G. Gellerstedt, Carbohyd. Res. 302 (1997) 213-218.

[24] A. Elsander, M. Ek, G. Gellerstedt, TAPPI J. 83 (2000) 73-77.

[25] T. Tamminen, M. Tenkanen, B. Hortling, in: Proceedings of the Third European Workshop on Lignocellulosic and Pulp, Stockholm, August 28-31, 1994, , pp. 84-88.

[26] B. Hortling, E. Turunen, J. Sundquist, Nordic Pulp Paper Res. J. 7 (1992) 144-151.

[27] Z.-H. Jiang, D.S. Argyropoulos, J. Pulp Paper Sci. 25 (1999) 25-29.

[28] G. Gellerstedt, L. Heuts, D. Robert, J. Pulp Paper Sci. 25 (1999) 111117.

[29] T. Tamminen, B. Hortling, in: D.S. Argyropoulos (Ed.), Advances in Lignocellulosics Characterization, TAPPI Press, 1999, pp. 1-42.

[30] S. Camarero, P. Bocchini, G.C. Galletti, A.T. Martínez, Rapid Commun. Mass Spectrom. 13 (1999) 630-636. 